\title{
MAKING ACCESS TO GOVERNMENT DATA WORK ${ }^{1}$
}

\author{
by \\ MIREILLE VAN EECHOUD*
}

The EU Directive on Re-use of Public Sector Information of 2013 (the PSI Directive) is a key instrument for open data policies at all levels of government in Member States. It sets out a general framework for the conditions governing the right to re-use information resources held by public sector bodies. It includes provisions on non-discrimination, transparent licensing and the like. However, what the PSI Directive does not do is give businesses, civil society or citizens an actual claim to access. Access is of course a prerequisite to (re)use. It is largely a matter for individual Member States to regulate what information is in the public record. This article explores what the options for the EC are to promote alignment of rights to information and re-use policy. It also flags a number of important data protection problems that have not been given serious enough consideration, but have the potential to paralyze open data policies.

\section{KEY WORDS}

Access to Government Information, Directive 2003/98/EC, Re-use of Public Sector Information, Open Data, Data Protection, Freedom of Information

1 This article is largely based on the policy recommendation of the EC Thematic Network on Legal Aspects of Public Sector Information ('LAPSI 2.0'), Working Group Access and Privacy, Access to Public Sector Information. Chair and author M van Eechoud. Contributors: Austere L, Broomfield H, De Terwanghe C, Ellis J, Hittmar G, Morando F, Lubarda M, Van Loenen B, Sappa S \& M de Vries. Many thanks to: M Caspers, S Eskens, S Van Velze \& P Leerssen at IViR for research assistance. LAPSI outputs are available at http://www.lapsiproject.eu/outputs [viewed 1 Aug. 2015].

M.M.M.vanEechoud@uva.nl, Prof. dr. Mireille van Eechoud is Professor of Law at the Institute for Information Law (IViR), University of Amsterdam (NL). 


\section{INTRODUCTION}

The societal benefits ascribed to making public sector information available for re-use are many. It is said to stimulate innovation and economic growth, political accountability and democratic participation, and increasingly also to increase public sector service delivery and efficiency. ${ }^{2}$ Without access to information, no re-use is possible of course. Considering that the Re-use of Public Sector Information Directive of $2013^{3}$ (the PSI Directive) promotes re-use, but does not regulate access, the question is how European policymakers might promote growth in the quantity and quality of information resources available. Before we turn to that issue, a brief introduction to the PSI Directive's main objectives and provisions is in order (section 1.1). Further, we set out why 'freedom of information' acts are a key building block of re-use policy (section 1.2). This will allow us to subsequently discuss what specific features of (national) freedom of information laws are of particular relevance to re-use policy (section 2). For all this, we draw upon the 'Good Practices' analysis developed by the Working Group Access and Privacy of the EC Thematic Network on Legal Aspects of Public Sector Information ('LAPSI 2.0'). ${ }^{4}$ We then highlight some other routes that may lead to increased availability of public sector data (section 3). One big challenge is how re-use policy - including open data policies - can be made to comply with data protection norms. This article highlights a number of the more pertinent problems that the EU still needs to address for its re-use policy to succeed (section 4), and then sums up the findings and suggests ways forward (section 5).

\footnotetext{
2 See e.g. EC Guidelines on recommended standard licences, datasets and charging for the reuse of documents, O.J. 2014/C 240/01 (hereafter: EC Re-use guidelines); UK Cabinet Office 2013, G8 Open Data Charter and Technical Annex, viewed 1 Aug 2015, $<$ https://www.gov.uk/government/publications/open-data-charter/g8-open-data-charterand-technical-annex>; World Bank, 2014, Open Data for Economic Growth, viewd 1 Aug 2015 https://openknowledge.worldbank.org/handle/10986/19997 License: CC BY 3.0 IGO. EC 2011, Communication on Open Data. COM(2011) 882 final.

3 Directive 2003/98/EC of the European Parliament and of the Council of 17 November 2003 on the re-use of public sector information, O.J. 2003, L345/90; Directive 2013/37/EU of the European Parliament and of the Council of 26 June 2013 amending Directive 2003/98/EC on the re-use of public sector information. O.J. 2013, L175/1.

4 Van Velze S, Caspers M, Eskens, S \& M van Eechoud, Good practices collection on access to data (with contributions of Austere, L, Broomfield H, Ellis J, Myska M, Lubarda M, ValeroTorrijos J, Pardo-López M, Van Loenen B, Grothe M, Vrecar S, \& De Vries, M), LAPSI, viewed 1 Aug 2015, <http://www.lapsi-project.eu/outputs>, hereafter: LAPSI Good practices access to data.
} 


\subsection{THE PUBLIC SECTOR INFORMATION DIRECTIVE AT A GLANCE}

The sets out a general framework for the conditions governing the right to re-use information resources held by public sector bodies, which includes provisions on non-discrimination, transparent licensing, pricing principles, and redress. It is the main EU legal instrument for stimulating the creation of value added information products and services (tools, apps, content) that take public sector information or data as a (main) source. Through minimum harmonization of national rules and practices, the PSI Directive is meant to create a more level playing field across the EU/EFTA. European companies (and citizens) can then better exploit the full potential of re-using data produced by or for the public sector. As such, the PSI Directive is a key instrument for open data policies at all levels of government in Member States. Open government data are a feature of most, if not all, open government agendas, as is evident from the action plans submitted by the EU and Member States in the context of the Open Government Partnership. ${ }^{5}$ Open public sector data involves making machine-readable data (sets) available for any re-use without restrictions or licensing fees. ${ }^{6}$ As such, it is a subset of the broader categories of re-usable information that the PSI Directive regulates.

Briefly, the PSI Directive requires that documents held by public sector bodies are made available for commercial and non-commercial uses, but only when there are no third party intellectual property rights involved and when the information is public under local access regimes. The public cultural institutions subject to the Directive (museums, archives, and libraries) are expected, but not obliged, to allow re-use. The PSI Directive requires that permission to re-use be granted through nondiscriminatory and transparent terms. Any fees must be cost-based and preestablished; the default principle is that re-use is allowed at no more than cost of dissemination. The European Commission drafted guidelines that set out the preferred re-use terms. ${ }^{7}$ The Guidelines on licensing favour the use of open, liberal licences, in keeping with the licensing guidelines drafted by the LAPSI network. ${ }^{8}$

5 For an up to date list of participating countries and action plans, see: http/:www.opengovernment.org.

6 See OKFN, n.d., 'Open definition', viewed 1 Aug 2015, <http://www.opendefinition.org>

7 EC Re-use guidelines, see note 2.

8 Dulong De Rosnay, M et al. 2014, D5.2. Licensing Guidelines, LAPSI 2.0 Thematic Network, viewed 1 Aug 2015, http://www.lapsi-project.eu/sites/lapsi-project.eu/files/D5.2Licensing GuidelinesPO\%20\%281\%29.pdf, hereafter: LAPSI Licensing guidelines. 


\subsection{THE ROLE OF RIGHT TO INFORMATION ACTS}

To be able to (re)use government information naturally requires access. However, the PSI Directive itself does not oblige Member States to provide access. Traditionally the legislative competences of the EU to regulate access to public sector information held by authorities in Member States are limited. ${ }^{9}$ This is why the EU chose to piggyback on national and regional public access regulation. The PSI Directive applies only to 'documents' that are already publicly accessible under national rules (art. 1(3) PSI Directive). The Directive obliges Member States to allow re-use of such documents. In these terms, the PSI Directive of 2013 is a big step forward compared to the original PSI Directive of 2003 that only encouraged Member States to allow re-use.

So do national access regimes support re-use? This is a question that the EC Thematic Network on Legal Aspects of Public Sector Information ('LAPSI 2.0') asked itself. Led by the University of Amsterdam's Institute for Information Law, the partner institutions in the Working Group Access and Privacy performed an analysis of 'good practices', to establish what particular attributes of freedom of information laws contribute to facilitating re-use, and how common these attributes are. ${ }^{10}$ The focus was on access to (official) information laws at Member State level. Such acts are known under different names, e.g. as 'freedom of information acts' ('FOIA'), 'right to information laws', 'transparency acts' or 'public records acts'. Freedom of information laws are the generic instruments in most national jurisdictions. In the past decade or so they have spread across the EU. ${ }^{11}$ In earlier work, the LAPSI network had concluded that freedom of information acts traditionally are not tailored to re-use. ${ }^{12}$ Indeed, some access laws explicitly forbid any (commercial) re-use of public records. Still, if one considers a pool of different acts, it is possible to tease out 're-use' friendly features.

\footnotetext{
9 Van Eechoud, M and Janssen, K, n.d., Policy Recommendation N. 6, Rights of Access to Public Sector Information, viewed 1 Aug 2015, <http://www.lapsi-project.eu/outputs>.

10 See LAPSI Good practices access to data, note 4.

11 Especially the Member States in Central and Eastern Europe now score well on right to information ratings, see <http://www.rti-rating.org/files/docs/Report.13.09.Overview\%20of \%20RTI\%20Rating.pdf <, viewed 1 Aug 2015.

12 Van Eechoud, M \& Janssen, K 2012, 'Rights of Access to Public Sector Information', Masaryk University Journal of Law and Technology, vol. 6, no 3.
} 


\section{RE-USE SUPPORTIVE FEATURES OF ACCESS LAWS}

The LAPSI survey assessed freedom of information laws from various jurisdictions along three dimensions. ${ }^{13}$ Specifically, it analysed to what extent provisions contribute to

- making PSI discoverable, because re-users will need to know what information or data public sector bodies hold and what its characteristics are;

- making PSI available, because the more information types and institutions are covered, and the fewer the limitation to access, the larger the data pool is;

- ensuring data is usable, by providing norms that address e.g. format, machine-readability, granularity, timeliness, completeness, accuracy, or delivery modes.

The Good practices inventory and analysis took the perspective of reusers and in particular worked from the assumption that ideal access laws:

1. Ensure the widest possible access to resources

2. Limit the restrictions to what can be done with the information;

3. Provide legal certainty on what uses can be made;

4. Respect user preferences concerning e.g. format of mode of delivery;

5. Help to reduce search costs;

6. Give re-users a voice in decision-making on what data are actively released and how.

Directly relevant to the re-use potential of information is the principle of non-discrimination. In the PSI Directive itself this means all (groups) of re-users must be treated equally (art. 10 PSI Directive). In FOIA it has a different meaning: a person need not show a particular (legally recognized) interest in obtaining access. Rather, the public interest in transparency is taken to be present, which translates into a system of 'access for all'. This is a very common feature of FOIAs. The distinction between public and privileged access matters because the PSI directive only applies in the former case. For information that is subject to privileged access, Member States do not have to ensure that re-use is allowed.

13 These three dimensions were already among those recognized by the Dutch government when it first started to develop an integral policy for opening up public sector information in the late 1990s. See Records of Parliament (Tweede Kamer) 1996-1997, 20644, nr. 30; and Beers A. 1996, Informatica Publica. Rathenau Instituut, Den Haag. 
Which institutions are subject to public disclosure rules, what type of resources are covered, what the permitted grounds for refusing disclosure are, all these directly affect the pool of information to which the re-use obligations of the PSI Directive apply. These availability factors are central aspects of any FOIA. National laws can differ substantially on those points. For example, some will cover most institutions that are a 'public sector body' within the meaning of the PSI Directive, ${ }^{14}$ while others only capture a limited part of the public sector, e.g. not apply to the judiciary. Most laws recognize a variety of interests that justify nondisclosure. Public security, privacy, third party commercial or intellectual property rights are common countervailing interests that limit public access. Naturally, the fewer the limitations, and the narrower their scope, interpretation and application, the better availability is.

Availability has another important dimension however, and it is one that many FOIAs are silent on: this concerns points two and three of the list above. Having a right to access information does not necessarily imply that subsequent uses of the information are free from permissions, or that it is clear when and on what grounds permission is needed from whom. Licences and (public domain) notices are key instruments used by public sector bodies to condition the use of information released under FOIA. Especially the most liberal 'open' licenses generally fit well with basic principles of freedom of information laws. ${ }^{15}$ The LAPSI network has produced licensing guidelines for public sector bodies. The guidelines identify essential building blocks for any licensing policy and outline steps a public sector body can take to establish if and how PSI can best be licensed. ${ }^{16}$ The PSI Directive itself does not prescribe a particular type of licensing, but only provides that terms and conditions must not be unnecessarily restrictive (art. 8 PSI Directive). The European Commission in its licensing guidelines clearly favours open licensing. ${ }^{17}$

\footnotetext{
14 Article 2(1) PSI Directive defines 'public sector body' as 'the State, regional or local authorities, bodies governed by public law and associations formed by one or several such authorities or one or several such bodies governed by public law'.

15 See Van Eechoud M, 2011, 'Friends or Foes? Creative Commons, Freedom of Information Law and the EU Framework for Re-Use of Public Sector Information' in L. Guibault \& C. Angelopoulos (ed.), Open Content Licensing: From Theory to Practice. Amsterdam University Press, Amsterdam.

16 LAPSI D5.2. Licensing Guidelines, see note 8. See also EC Re-use guidelines (see note 2), which equally advice the use of open licences.

17 See note 8 .
} 
Points 4 through 6 are aspects of discoverability and usability, and these are not particularly well developed in many access laws. The use of web directories, portals and in some countries FOIA specific 'electronic journals' aids discoverability. Overall, firm statutory obligations to pro-actively disclose information about what PSI is held, or pro-actively disclose PSI holdings itself for that matter, are rare. ${ }^{18}$ Where formal obligations exist or are being considered they are mainly geared towards making transparent what a given public sector bodies' tasks, policies and organizational structure are. It is safe to assume that such information does not have much (economic) re-use potential although from the public sector perspective and in the interest of transparency it is 'high value' information. Of note, the absence of formal obligations does not necessarily hinder the roll out of web directories and portals (with repository function) in Member States. ${ }^{19}$ The number of open government data portals for example grows steadily. ${ }^{20}$ Many offer the possibility to put in a request for the pro-active disclosure of a particular dataset, but such user-oriented features seldom have legal backing in right to information laws.

Many laws have some provisions that affect usability. A guiding principle in most FOIAs is that documents are provided 'as is'. At most a party seeking access may have a choice between formats that are already available (print, digital, a particular electronic format). The PSI Directive itself encourages public sector bodies to make documents available in machine-readable format accompanied by meta-data and using open standards (art. 5 PSI Directive). By doing so, it goes well beyond what the average FOIA prescribes. In terms of usability, the limitation of FOIAs to disclosing actual documents often means that a re-user has no claim to bulk data. Nor are FOIAs conceived with the supply of dynamic data in mind. Typically, a re-user would have to file repeat requests. Statutory response times are short in some countries, which positively affects usability of data. ${ }^{21}$

${ }^{18}$ A notable exception applies to the data themes covered by the 'INSPIRE' framework (see section of this paper).

19 De Vries, M. et al. 2011, The Pricing of Public Sector Information, study for the EC, Brussels, noted a steady increase of data portal/registries during the 2009-2011 period; we assume this trend has continued quite separately from freedom of information / right to information legislation reform.

20 See $<$ http://dataportals.org>, which contains a list of open data portals worldwide, covering all levels of administration (national, regional, local). 
Below is the table of the LAPSI Good practices collection on access to data report. ${ }^{22}$ It summarizes characteristic provisions in freedom of information acts that play a role in stimulating re-use. Items in italics are uncommon provisions in Freedom of Information Acts. The table illustrates that Member States wishing to closer align public access acts with EU re-use rules have plenty of options for reform.

\begin{tabular}{|c|c|c|c|}
\hline Helps make PSI: & \multirow{2}{*}{$\begin{array}{c}\text { Discoverable } \\
\text { (known what PSI is } \\
\text { where) }\end{array}$} & \multirow{2}{*}{$\begin{array}{c}\text { Available } \\
\text { (what PSI public, how to } \\
\text { get it, terms\&pricing) }\end{array}$} & \multirow{2}{*}{$\begin{array}{c}\text { Usable } \\
\text { (fit for purpose re-user) }\end{array}$} \\
\hline Good FOIA practice: & & & \\
\hline $\begin{array}{l}\text { Broad scope of } \\
\text { information \& bodies } \\
\text { covered }\end{array}$ & & $\sqrt{ }$ & \\
\hline $\begin{array}{l}\text { Few and narrowly } \\
\text { described limitations }\end{array}$ & & $\sqrt{ }$ & \\
\hline $\begin{array}{l}\text { Access for all (non- } \\
\text { discrimination) }\end{array}$ & & $\sqrt{ }$ & \\
\hline $\begin{array}{l}\text { Access to bulk \& dynamic } \\
\text { data }\end{array}$ & & & $\sqrt{ }$ \\
\hline Quick response times & & & $\sqrt{ }$ \\
\hline $\begin{array}{l}\text { Pro-active disclosure } \\
\text { duties }\end{array}$ & $\sqrt{ }$ & $\sqrt{ }$ & \\
\hline Online & $\sqrt{ }$ & $\sqrt{ }$ & \\
\hline Open format & & & $\sqrt{ }$ \\
\hline User led & & & $\sqrt{ }$ \\
\hline Search support & $\sqrt{ }$ & & \\
\hline Referral system & $\sqrt{ }$ & & \\
\hline $\begin{array}{l}\text { Information } \\
\text { registers / portals }\end{array}$ & $\sqrt{ }$ & & \\
\hline User preferred form & & & $\sqrt{ }$ \\
\hline Open formats & & & $\sqrt{ }$ \\
\hline Machine readable & & & $\sqrt{ }$ \\
\hline No or low costs of access & & $\sqrt{ }$ & \\
\hline $\begin{array}{l}\text { Efficient review access } \\
\text { procedure }\end{array}$ & & $\sqrt{ }$ & $\sqrt{ }$ \\
\hline
\end{tabular}

Table 1: Freedom of information laws characteristics conducive

to promoting re-use of PSI (LAPSI 2.0 Good practices, June 2014)

21 Another question is how the availability, quality and speed of redress mechanisms affect the usability of data. Obviously the availability of low barrier, speedy review procedures in case of refusal to disclose information (or imposition of unfavourable conditions of use) affects the re-use potential of government data. If proceedings are slow, data might for example be outdated by the time it is released. Procedural and enforcement issues are addressed by: Hugelier S, Janssen K \& Dos Santos C , 2014, LAPSI 2.0 Good practices on Institutional embedding and enforcement and by Valero J \& Magnolia Pardo M, 2014, LAPSI Position paper on Enforcement and Institutional Embedding.

22 See note 4 . 


\section{ALTERNATIVES TO FOIA AS INSTRUMENT FOR RE- USE POLICY}

From the above it is clear that although access is the at the basis of re-use regimes, access to information laws play a limited role in stimulating discoverability and usability of PSI for re-use purposes. Discoverability is a recognized problem for cultural heritage institutions as well. ${ }^{23}$ A flagship project like Europeana is exceptional in the effort put into this, and in making metadata on cultural collections available for re-use under the Creative Commons public domain dedication.

As was noted in the LAPSI Good practices collection on access to data report, current freedom of information laws serve primarily as instruments for re-active disclosure of existing documents on a case-by-case basis, in aid of making governments accountable. Pro-active disclosure obligations come second at best. ${ }^{24}$ The wheels of FOIA reform turn slowly ${ }^{25}$ and are driven by Member States themselves. It is therefore a legitimate question how productive it would be for the EU to focus on FOIA as instruments to improve re-use or even of open data policy. An additional political challenge is the lack of credibility. The EU institutions have not been able to agree on the much-needed reform of the principal piece of law that governs access to their own documents: Regulation 1049/2001 regarding public access to European Parliament, Council and Commission documents. ${ }^{26}$ It seems plausible that this incapacity adversely affects the political authority to convince Member States they should engage in reform themselves.

23 This is at least suggested by the Curtis Cartwright Consulting, 2011. Final report on PSI reuse in the cultural sector (CC462D011-1.1), Guilford. Report commissioned by the EC.Viewed 1 Aug 2015.

<http://ec.europa.eu/information_society/newsroom/cf//document.cfm?doc_id=1148>

24 On the role of pro-active disclosure obligations, see Darbishire, H. 2011, Proactive Transparency: The future of the right to information? A review of standards, challenges, and opportunities, World Bank Institute, Washington.D.C. viewed 1 Aug 2015, < http://siteresources.worldbank.org/EXTGOVACC/Resources/DarbishireProactiveTranspare ncy.pdf $>$.

25 Some countries do take drastic steps however: a new Greek law (number 4305/31.10.2014) for example obliges public sector bodies to register any datasets/resources that they hold and indicate for each resource whether it is exempt from the new default rule that all government information made public is freely re-usable [information supplied through LAPSI network, personal email of Greek Ministry of Administrative Reform and EGovernment, Department of Permanent Law Codification.

26 Regulation (EC) No 1049/2001 of the European Parliament and of the Council of 30 May 2001 regarding public access to European Parliament, Council and Commission documents. O.J. 2001, L 145/43-48. 


\subsection{IMPROVING KNOWLEDGE OF SECTOR SPECIFIC REGULATION} Apart from access laws, Member States have a host of other laws that regulate specific types of public sector information. They concern registries in the areas of e.g. companies, land, electoral rolls as well as activities of shared facilities e.g. statistics, meteorological data and spatial information. It was well beyond the scope of the LAPSI network (which was not a research network) to analyse exactly what type of information obligations and access rights are 'out there'. There was and is precious little (academic) literature on the topic. Yet it seems likely that among the data resources subject to specific regulation are data that are particularly interesting to prospective re-users. So an unanswered question is which access regulations exists outside FOIA, and how opening up the data resources they cover might contribute to the creation of cross-border information products and services, whether commercial or not-for profit.

The LAPSI Good practices collection on access to data report discusses some examples, e.g. on how the national regulatory framework for meteorology and companies registers in The Netherlands and Norway enable re-use. However, this only scratches the surface so to speak. EU and national policy makers cannot hope to promote efficient re-use policies if at the source it is unclear what data has (legal) status as publicly accessible.

Of particular interest are so-called 'key' or 'base' registries and datasets. These are considered as core components of national information infrastructures. Because many public sector bodies rely on them for either the exercise of public tasks, and/or because they have an important function in society at large. Business registers for example facilitate commercial transactions, while vehicle registries are important for taxation, road safety and environmental policy purposes. Key data sets exists in many different domains, e.g. they can be about persons (population or electoral registers), vehicles, real estate ownership, companies, public procurement (tenders, contracts), but also include spatial data under the INSPIRE directive. ${ }^{27}$ Leaving aside security and privacy issues, base registers can be of considerable interest to prospective re-users who seek to develop novel information services.

\footnotetext{
27 Directive 2007/2/EC of the European Parliament and of the Council of 14 March 2007 establishing an Infrastructure for Spatial Information in the European Community (INSPIRE), O.J. L 2007 108/1-14.
} 
For the most part, base registries are set up and regulated at national or regional level. There are European initiatives that deal with base registries. The 'Interoperability Solutions for European Public Administrations' (ISA) programme already addresses some 'legal' interoperability issues of base registers. However, semantic and technical interoperability issues for cross-border exchange of register data dominate. ${ }^{28}$ It is also important to note that the focus of ISA is not on re-use but on facilitating cross-border cooperation between public sector bodies. Ultimately, this allows more efficient and better public service delivery. Some impact of the PSI Directive does however show. For example, the ISA Work Program Access to Base Registries final report ${ }^{29}$ advises public sector bodies that operate base registers to opt for re-use enhancing business models. The EU has also legislated to improve public access to cross-border company information, ${ }^{30}$ but re-use appears not to be an aspect taken wholly on board yet. Even though no comprehensive view of rights to access register data exists, from the examples discussed in the context of the LAPSI network it seems safe to assume that the legal diversity that marks national freedom of information regulation is at least as big for register data. It makes sense then to develop a strategy that ensures re-use is included as an issue in future programmes aimed at improving EU wide accessibility to national base registries.

\subsection{SECTOR SPECIFIC REGULATION}

The PSI Directive is a generic instrument. It applies to a very broad range of public sector actors and to a plethora of information types. That is why it sets out broad principles rather than specific rules. Promoting re-use as a tool toward innovative information services may require sector specific regulatory approaches. For example, the provision of multi-modal transport data and (other) traffic information services takes place in a complex and highly dynamic field of public and private actors, where (unfair) competition issues are a particular concern. This is why the authors of the final report on EU-wide real-time traffic information services (for DG

\footnotetext{
28 ISA Work program, Feb. 2014, Access to base registries, final Report, EC, Brussels. Viewed 1 Aug. 2015, <[http://ec.europa.eu/isa/documents/final-report_en.pdf>.

29 See note 28 .

30 Directive 2012/17/EU on interconnection of business registers, O.J. 2012, L 156/1.
} 
MOVE) suggest that formalising rules for access and re-use of data sets might be desirable. ${ }^{31}$

An example of already existing sector specific regulation is the INSPIRE framework mentioned above. ${ }^{32}$ It consists of the INSPIRE Directive and implementing rules and technical specifications. The Directive lays down general rules aimed at the establishment of the Infrastructure for spatial information in the European Community. Strictly speaking this was done for the purposes of Community environmental policies and policies or activities which may have an impact on the environment (art. 1 INSPIRE Directive). However, once in place the infrastructure can also serve other public (and private) activities. The framework includes measures that address exchange, sharing, access and use of interoperable spatial datasets and spatial data services across the various levels of public authority and across different sectors. INSPIRE applies to a wide range of 34 content themes, from specific geographic reference data themes (e.g. transport networks, cadastral parcels, buildings, elevation, statistical and administrative units) to environmental themes (e.g., geology, habitats and biotopes, human health and safety, meteorology, hydrology, oceanographic features). All INSPIRE datasets and services are required to be pro-actively published through the INSPIRE geoportal at the European community level. ${ }^{33}$ With the requirement to provide datasets and services metadata, the obligation to conform to INSPIRE data specifications, and the requirement to provide access through discovery, view, and download services, INSPIRE makes a very important contribution, in particular to the legal and physical attainability of public sector spatial information as well as to its usability.

\subsection{PRACTICAL POLITICS: FOCUS ON RELEASE OF HIGH VALUE DATASETS}

When it comes to policy choices for the EU, it might well be that the road to reform and ultimately harmonization of national freedom of information

\footnotetext{
31 Van de Ven, T. \& Wedlock, M., 2014, ITS Action plan, D5 - Final Report Action B - EU-wide real-time traffic information services, Brussels, p.42-43, viewed 1 Aug 2015. $<$ http://ec.europa.eu/transport/themes/its/studies/doc/2014-07-its-action-plan-d5-actionb.pdf $>$.

32 Based on Loenen, B, van, and Grothe, M., 'INSPIRE empowers re-use of public sector information', International Journal of Spatial Data Infrastructures Research 2014, vol.9 , p. 96106.

33 The INSPIRE portal is available at http://inspire-geoportal.ec.europa.eu/
} 
laws is not an obvious one to pursue in the service of improving re-use possibilities. Predominantly because the EU legislative's competence is very limited here and cultures of transparency still differ substantially among Member States. As was said, on top of those problems one can argue that as long as the EU institutions do not succeed in reforming their own access regulation, there is a lack of credible political leadership. Pursuing practical objectives through political commitments on the other hand seems to be strategy that is already bearing fruit.

The economic studies on the (potential) value of PSI re-use that the EC and national government have commissioned in the past decade already tried to identify areas where re-use potential is high. Legal information, geographic information, patent registers, statistics and company information are often identified as such. ${ }^{34}$ Initiatives that are more concrete now exist at all levels of government in many countries and at European, even global level. The 2014 Commission PSI Guidelines ${ }^{35}$ identify actual datasets that are 'high value' and should be released with priority. So does the G8 Open Data Charter. The latter ${ }^{36}$ identifies a number of areas with high value data sets that the G8 countries (EU members: UK, France, Italy) have undertaken to release for re-use purposes under the 'open by default' principle. The lists include company data, statistics, mapping, postcodes and transport data such as timetables of public transport. Typically, these resources are subject to specific laws and regulations, and agreements in public private partnerships. The EU has endorsed the Charter. EU funded research by Price Waterhouse Coopers has identified over 250 data sets at EU institutions that are considered 'high value' and could be prioritized for active release. The research took in account the results of a number of (national) public consultations, surveys, and reports by other consultants. ${ }^{37}$ In the G8 EU Action plan, the EU has committed not only to releasing high value datasets held by its own institutions, but also to

\footnotetext{
34 See the overview of studies in Van Eechoud, M (2015 forthcoming), 'Calculating and Monitoring the Benefits of Public Sector Information Re-use', in Thomas Dreier et al. (eds.), Zugang und Verwertung öffentlicher Informationen, Nomons, Baden.

35 Commission Re-use guidelines, see note 2.

36 Technical annex at 6.2, UK Cabinet Office 2013, G8 Open Data Charter and Technical Annex, viewed 1 Aug 2015, <https://www.gov.uk/government/publications/open-data-charter/g8open-data-charter-and-technical-annex>.

37 Bargiotti, I.et al., 2014, Value based prioritisation of Open Government Data Investments (EPSI platform topic report no. 2014/08), PwC, viewed 1 Aug 2015,
} 
encourage Member States to do the same. ${ }^{38}$ The Commission PSI Re-use guidelines as we have seen indeed recommend that Member States release high value datasets; they also give guidance on how to do this to make them attractive for re-use purposes (e.g. disclose in machine-readable form, online, with meta-data). The question whether this can all be achieved within Member States' existing regulatory frameworks is left undiscussed.

\section{DATA PROTECTION COMPLICATIONS}

Possible the biggest challenge to re-use and open data policies is the need to develop instruments that ensure compliance with data protection laws. From the work done in the first LAPSI network in 2011-2012 it was already apparent that data protection law and re-use policy can be difficult to reconcile. ${ }^{39}$ The 2013 Opinion of $\mathrm{WP} 29^{40}$ on open data and public sector information ('PSI') re-use proposed that part of the solution is for public sector bodies to engage in 'data protection by design and default' and perform data protection impact assessments so that data protection concerns are addressed prior to any release of PSI for re-use purposes. This is sound advice of course to help prevent (inadvertent) breaches of data protection laws, but does not deal with the more fundamental problems.

\subsection{KEY TENSIONS UNDER THE PROPOSED DATA PROTECTION REGULATION}

The LAPSI 1.0 network Recommendation on data protection focussed on the situation under the current Data Protection Directive. The negotiations on the proposed Data Protection Regulation are now in the final stages. The texts of the trilogue talks suggest the challenge become bigger. This is not

<http://www.scribd.com/doc/238741083/Value-Based-Prioritisation-of-Open-GovernmentData-Investments>; See also ISA report, note 30, and McKinsey \& Company, 2013. Open data: Unlocking innovation and performance with liquid information, viewed 1 Aug 2015. $<$ http://www.mckinsey.com/insights/business_technology/open_data_unlocking_innovatio n_and_performance_with_liquid_information>.

38 EU Implementation of the G8 Open Data Charter (Oct. 2013), viewed 1 Aug 2015, $<$ http://ec.europa.eu/digital-agenda/en/news/eu-implementation-g8-open-data-charter>.

39 See Dos Santos, C. et al. 2012, LAPSI Policy Recommendation 4: Privacy and Personal Data Protection and dos Santos, C., On Privacy and Personal Data Protection as Regards Re-use of Public Sector Information (PSI) (2012), Masaryk University Journal of Law and Technology, vol. 6, no 3. The Recommendation sketches problems not only for the public sector body allowing re-use, but for the re-using parties as well. That analysis still holds true.

40 Working Party on the Protection of Individuals with regard to the Processing of Personal Data (WP29), Opinion 06/2013 on open data and public sector information ('PSI') re-use, adopted June 2013. See also the earlier opinion $07 / 2003$ on the re-use of public sector information and the protection of personal data - Striking the (balance WP 83). 
the place to analyse the implications of the proposal in detail, but by highlighting a few issues we can give an idea of the complexities involved.

For those public sector resources that contain personal data, making it available for re-use -that is for uses other than the public task it was collected for - is highly problematic. Using personal information for unforeseen purposes or in a different context easily breaches the purpose specification principle that is central to the Data Protection Directive (and the proposed General Data Protection Regulation - (G)DPR). It holds that processing activities must not be incompatible with the (prespecified) purposes for which the data was collected..$^{41}$ Disclosing personal data constitutes an act of processing, and as such requires that it is legitimate on one or more of the six grounds enumerated in data protection law. From the perspective of public sector bodies, the most relevant grounds are: that the processing is 'necessary for the performance of a task carried out in the public interest or in the exercise of official authority vested in the controller' (art. 6(1)e DPR proposal), ${ }^{42}$ or necessary for compliance with a legal obligation (art. 6(1)c DPR proposal). It is uncertain how these grounds relate to obligations to actively or passively disclose data under freedom of information acts. WP29 is of the opinion that in the case of a legal obligation 'the law must fulfil all relevant conditions to make the obligation valid and binding, and must also comply with data protection law, including the requirement of necessity, proportionality and purpose limitation'. ${ }^{43}$ This suggest that in particular the usually rather vague obligations for public sector bodies to actively disclose information cannot be based on the ground of art. 6(1)c proposal DPR (equivalent of art. 7(f) Data protection directive).

A further legitimate ground might be that disclosure is 'necessary for the purposes of the legitimate interests pursued by the controller or by the third party or parties to whom the data are disclosed' (art. 6(1)f DPR proposal). This is subject to a balancing test: the fundamental rights and freedoms of the data subject can override the legitimate interest of the

${ }_{41}$ Art. 5(3) Proposal Data Protection Regulation reads (in both the original Commission text COM (2012) 11 and the Council text of 8 July 2015, doc 100391/15): 'collected for specified, explicit and legitimate purposes and further processed in a way compatible with those purposes'. The Council text elaborates that further processing for statistical, historical or scientific research and archiving in the public interests is (as such) not incompatible with the initial purposes (provided certain safeguards are met).

42 The references are to the 8 July 2015 text of the Council, unless noted otherwise.

43 Article 29 Working Party, 2014, Opinion 6/2014 on the notion of legitimate interests of the data controller under Article 7 of Directive 95/46/EC, adopted on 9 April 2014 (WP 217), p. 19. 
public sector body or recipient re-user. The European Commission has proposed that the 'legitimate interest' ground should no longer be available to public sector bodies, an idea supported by both the European Parliament and the European Data Protection Supervisor. ${ }^{44}$ As the Council opposes this change, it remains to be seen whether under the new Data protection regulation public sector bodies will indeed have less leeway. Finally, one further ground of legitimate processing is consent by the data subject. In the context of public access and re-use, there at least two problems. One is that in many instances the public sector body that collects data on an individual will be in position of power, making it doubtful that any consent given by the data subject (citizen) is freely given. Another problem is that the rationale of making data available for re-use is that the data can be put to alternative uses by many different re-users. However, in addition to being freely given the consent must also be 'specific' and 'informed'. Asking for consent to disclose data for unspecified re-uses by an indefinite group of re-users does not meet these requirements. ${ }^{45}$

Yet another complication arises if the Data Protection Regulation will contain a fairly specific test for establishing whether a use is in conformity with the purpose of initial collection. The Commission proposed that reasonable expectations of the data subject must be taken into account, as well as the consequences of the intended further processing for data subjects. Such case-by-case consideration of the effects of making data available for re-use is hardly compatible with the access for all; re-use for any purpose principles that are key to re-use and especially to open data policies.

The pervasive application of data protection rules to all types of PSI that until a few years ago would not be considered to count as personal data, also has major implications for re-use policy. In light of the ever increasing ease with which combining data leads to (near) identification of persons, more data held by the public sector will be considered personally identifiable information, which means disclosure (and downstream use) must be (G)DPR compliant. In addition, as the WP29 Opinion

\footnotetext{
${ }^{44}$ Art. 6(1)f proposal, COM (2012) 11, see Annex to EDPS Opinion 3/2015 Europe's big opportunity, Comparative table of GDPR texts with EDPS recommendation.

45 See for a discussion of the various requirements: WP29, 2011, Opinion 15/2011 on the definition of consent (WP187).
} 
on anonymisation ${ }^{46}$ shows, advances in de-anonymisation techniques make it increasingly difficult to robustly anonymise personal data.

The LAPSI network took no position on whether the broad application of data protection rules is undesirable from the perspective of stimulating PSI re-use. The PSI Directive itself recognizes that data protection must be respected, and this is also made explicit in many implementing laws in Member States. ${ }^{47}$ Whether the (G)DPR will contain a very explicit consideration on the primacy of data protection law over the right to re-use public information as enshrined in the PSI Directive is uncertain. ${ }^{48}$ The European Commission and European Parliament proposed to include a recital clarifying that disclosure of (personal) information by public sector bodies under access laws is allowed (recital 12a). The European Parliament favours a recital that specifies that such public access must be provided for by law and that access laws must balance the public interest in access with privacy concerns. The Council text of 8 July 2015 (recital 121a) firmly puts data protection before public access and re-use interests by providing that the PSI Directive 'leaves intact and in no way affects the level of protection of individuals with regard to the processing of personal data under the provisions of Union and national law, and in particular does not alter the obligations and rights set out in this Regulation'. But the Council text also provides that access and re-use laws 'should reconcile public access to official documents and the reuse of public sector information with the right to the protection of personal data and may therefore provide for the necessary derogations from the rules' [of the Data protection regulation]. The proposed Council text for articles 88a and 88aa explicitly allow the disclosure for access and re-use purposes, but speaks of 'reconciling' the various interests, not of putting data protection interests first.

It is uncertain yet what the precise hierarchy of norms will be and how it will play out for re-use policy. Especially where pro-active publication

46 WP29, 2014, Opinion 05/2014 on Anonymisation Techniques (WP217).

47 See the overview in the LAPSI Policy Recommendation No. 4 on Data protection, note 40.

48 The proposal by the Presidency (16140/14 of 1 Dec. 2014), art. 88a read: 'Personal data in in public sector information held by a public authority or a public body or a private body for the performance of a task carried out in the public interest may be disclosed by the authority or body in accordance with Union law or Member State law to which the public authority or body is subject in order to reconcile the re-use of such official documents and public sector information with the right to the protection of personal data pursuant to this Regulation'. The Commission has made a reservation on this draft provision, as it judges it incompatible with the PSI Directive (which leaves data protection law intact). 
of data is concerned, specific statutory rules in which the societal interests concerned with transparency and re-use have been carefully balanced against fundamental privacy interests of citizens seem called for. For if it is indeed the case that pro-active transparency stimulates re-use most, the lack of clear legal obligations to release data in the absence of a specific request might prove to be the legal Achilles heel of successful re-use policy.

The (G)DPR will likely leave manoeuvring room for Member States to maintain or introduce national provisions to further specify the application of the data protection rules of the regulation to public sector bodies. But just how much room must remain is debated. ${ }^{49}$ One could take the perspective that such space can serve as a useful 'test bed', possibly yielding different ways of reconciling national pro-active and re-active disclosure duties and corresponding re-use permission with data protection rules.

\subsection{RE-USE VERSUS OPEN DATA POLICIES}

The current trend among policy makers to frame re-use as 'open data' policy has a dual effect. Open data means data that is among other things available for everyone to put to any use, with no restrictions imposed by the organisation that releases the data. ${ }^{50}$ This does not mean that the recipient is not bound by data protection rules of course. But from the perspective of the public sector, to provide access to all with no conditions attached makes it particularly difficult to comply with data protection rules. The neteffect of pushing open data as the standard model to aspire to may be that PSBs are driven to exclude all personal data and data relating to identifiable persons from their re-use policies. This is not what the current Data Protection Directive and the proposed (G)DPR require. ${ }^{51}$ An exclusion approach has the advantage of being simple, but has far-reaching impact considering the broad application of data protection law. Especially since data protection rules also apply to data that pertains to identifiable persons. The European Commission position is that to determine whether this is the

\footnotetext{
49 See e.g. Presidency note to Council of 1 December 2014, Doc. 16140/14 on the General Data Protection Regulation.

50 See OKFN, 'Open definition', viewed 1 Aug 2015, <opendefinition.org> for a more elaborate explanation of the eight principles of open data. (Some would argue nine if one includes costs). What are relevant to our purposes are the twin conditions that access is open to all, and with no conditions attached (or at most an obligation to recognize the source or share alike).

51 For example, both contain provisions that explicitly allow re-use for scientific, statistic and historical purposes, on condition that certain additional safeguards are in place.
} 
case account should be taken of 'all the means likely reasonably to be used' either by the PSB itself or any third parties. ${ }^{52}$ That is a broad norm, bearing in mind that the increased availability of datasets and the possibilities for linking data makes identification easier.

Note that the adoption of 'open data' is not is not what the PSI Directive prescribes. In the PSI Directive what matters are transparent, accessible and non-discriminatory terms of use. If re-use is to be data protection compliant (as the PSI Directive recognizes it should be) the possibility of imposing use restrictions and conditions is arguably of paramount importance.

\subsection{TAILORING RE-USE TO DATA PROTECTION NORMS}

In its Re-use guidelines ${ }^{53}$ the Commission took up WP29 recommendation that PSBs actively inform re-users of the applicability of data protection rules. It might be worthwhile to explore whether it is useful to develop standard 'privacy notices' or 'privacy licensing terms' which give re-users more (formal) guidance on how to ensure processing is data protection compliant. Ensuring early development of standard notices might prevent proliferation of notices and licensing terms that in the context of intellectual property are considered as a barrier for the development of information services and products built on different data sources. It is conceivable that various privacy licensing terms are developed depending on the level of privacy risk involved, e.g. release of postal codes carries more risk (depending on the granularity of the local postcode system of course) than the release of say aggregate housing prices. The PSI Directive, in allowing public sector bodies to set different terms for different types of re-uses is no barrier to such differentiation. All it demands is that the terms and conditions are non-discriminatory against individual re-users.

A more tailored approach might ensure that the benefits of opening up PSI for re-use are not lost simply because data protection law applies. The proposed provisions in the $(\mathrm{G}) \mathrm{DPR}$ on the processing of personal data for historical, statistical or scientific purposes and for archiving purposes, and the special status for persons and institutions using personal data for academic, artistic and journalistic purposes all point towards the possibility -desirability even- of distinguishing between different types of re-use.

52 Art. 4(1) Commission proposal COM (2012) 11.

53 See note 2. 
At any rate, even if a specific provision would make it into the $(G) D P R$ which explicitly allows disclosure of personal data contained in PSI for reuse purposes, there still is a requirement to balance the public interest in reuse against the concrete privacy interest at stake. The prospects of one-sizefits all open data policies therefore seem limited.

The underlying fundamental tensions need addressing too. This requires in depth research into normative aspects: what are the competing interests involved (e.g. public interest in economic growth, better service delivery, and accountable government) and what are the balancing mechanisms suited for resolving them? How can these be operationalized in instruments that can aid public sector bodies in deciding which datasets can be released under what conditions and for which re-use purposes? What tools might be developed to aid citizens in exercising some control over the re-use of data that relates to their person? How can the potential for re-use be maximized in the space of the (soon to be) Data Protection Regulation? These are complex questions that would benefit from a thorough legal analysis flanked by adequate expert technological, public administration, business and civil society input.

\section{WHERE NEXT?}

The claimed benefits of opening up public sector data for re-use are manifold, but can y: development of innovative products and services, better public service delivery, increased accountability and public participation to name a few often mentioned. To what extent those benefits materialize, is still largely a matter of speculation. ${ }^{54}$ With the Public Sector Information Directive as the chief instrument, the EU has so far concentrated its efforts on a generic regulatory approach, which builds on and thus utterly depends on-- a very diverse landscape of local access norms. Although reform of access laws is one way to ensure that the availability, discoverability and usability of public sector data improves, there are other possibly faster and more effective ways. As the Open Government Partnership shows, 'softer' approaches that focus on political commitment to achieve concrete actions - e.g. the national open data action plans, the identification and release of high value datasets - are valuable too.

54 For a critical discussion of these perceived benefits, see Van Eechoud, M, 2015 (forthcoming), 'Calculating and Monitoring the Benefits of Public Sector Information Reuse', in Thomas Dreier et al. (eds.), Zugang und Verwertung öffentlicher Informationen, Nomos, Baden. 
The EU develops policy and regulates across multiple domains with impact on access to and re-use of public sector information, e.g. in the field of statistics, transport, public spending, spatial information (e.g. INSPIRE, satellite observation data), basic registries and legal information. The removal of legal barriers to re-use should ideally be a standard element of such programmes, and especially of the legal interoperability agendas pursued as part of the European Interconnection Strategy and the 'European Interconnection Framework' (EIF). To what extent hard regulation is necessary is a question that needs asking constantly. The development of a comprehensive vision on the role of legal norms in realizing the economic and social potential of wider use of PSI will require a better understanding of current domain specific laws and their interactions, both in member states and at EU level.

One of the biggest challenges is how to reconcile privacy and data protection with increased circulation of public sector information. The PSI Directive recognizes that data protection rules and generally law protecting privacy must be adhered to, but how this can be done is an increasingly difficult question to answer. If public sector bodies adopt the precautionary principle, that is: when in doubt about downstream data protection implications, do not release data for re-use at all, then many types of data might not be released. This is especially true in cases when (downstream) linking of data, which taken in isolation are not personal data as such, causes individuals to be identifiable and the combination of the data thus represents personal data.

The challenges are not only posed by technological developments (deanonymisation techniques, linking of data from multiple sources). There are some fundamental tensions between core principles of data protection law and the notion of re-use, especially re-use as open data. More effort seems needed at the short term practical level, notably raising data protection awareness and developing mechanisms that help public sector bodies comply with data protection rules in the pursuit of implementing re-use policy. Of note, the move in recent years towards promoting open data as the re-use model to aspire to does not necessarily help to ease the tension between access/re-use on the one hand and data protection concerns on the other. Enabling anyone to use PSI for their own purposes - a central element of open data policy - implies that no terms/restrictions can be set in the interest of data protection. Such restrictions however are mandated 
by the PSI Directive and can very well comply with its non-discrimination principle. To the extent that open data licensing is promoted as the ideal to aspire to for PSBs, it might cause substantial numbers of datasets to be excluded from re-use. It would seem therefore that more moderate policies, or possibly enriching open licences with data protection terms can help PSBs overcome data protection concerns and more readily release data for re-use.

\section{LIST OF REFERENCES}

Bargiotti, I et al., 2014, Value based prioritisation of Open Government Data Investments (EPSI platform topic report no. 2014/08), PwC.

Beers A. 1996, Informatica Publica. Rathenau Instituut, Den Haag.

Curtis Cartwright Consulting, 2011, Final report on PSI re-use in the cultural sector (CC462D011-1.1), commissioned by the EC.

Cristina dos Santos, On Privacy and Personal Data Protection as Regards Re-use of Public Sector Information (PSI) (2012), Masaryk University Journal Law and Technology, vol. 6, no 3.

Darbishire, H. 2011, Proactive Transparency: The future of the right to information? A review of standards, challenges, and opportunities, World Bank Institute, Washington.D.C.

Dulong De Rosnay, M et al. 2014, D5.2. Licensing Guidelines, LAPSI 2.0 Thematic Network, viewed 1 Aug 2015, <http://www.lapsi-project.eu/sites/ lapsi-project.eu/files/D5.2LicensingGuidelinesPO\%20\%281\%29.pdf>

Hugelier S, Janssen K \& Dos Santos C , 2014, LAPSI 2.0 Good practices on Institutional embedding and enforcement, viewed 1 Aug 2015, $<$ http://www.lapsi-project.eu/sites/lapsi-

project.eu/files/D4.1.GoodPracticesRedressFinalVersion.pdf $>$.

ISA Work program, Feb. 2014, Access to base registries, final Report, EC, Brussels.

Loenen, B, van, and M. Grothe, 'INSPIRE empowers re-use of public sector information', International Journal of Spatial Data Infrastructures Research 2014, vol. 9. 
McKinsey \& Company, 2013. Open data: Unlocking innovation and performance with liquid information, viewed 1 Aug 2015, $<$ http://www.mckinsey.com/insights/business_technology/open_data_un locking_innovation_and_performance_with_liquid_information>.

Valero J \& Magnolia Pardo M , 2014, LAPSI Position paper on Enforcement and Institutional Embedding, viewed 1 Aug 2015 http://www.lapsiproject.eu/sites/lapsi-pro-ject.eu/files/D4.2\%20Position\%20paper\%20on \%20Enforcement\%20and\%20Institutional\%20Embedding.pdf.

Van de Ven, T \& Wedlock, M, 2014, ITS Action plan,D5 - Final Report Action $B$ - EU-wide real-time traffic information services, Brussels.

Van Eechoud M, 2011, 'Friends or Foes? Creative Commons, Freedom of Information Law and the EU Framework for Re-Use of Public Sector Information' in L. Guibault \& C. Angelopoulos (ed.), Open Content Licensing: From Theory to Practice. Amsterdam University Press, Amsterdam.

Van Eechoud, M, 2015, 'Calculating and Monitoring the Benefits of Public Sector Information Re-use', in Thomas Dreier et al. (eds.), Zugang und Verwertung öffentlicher Informationen, Nomos, Baden (forthcoming).

Van Eechoud, Mireille \& Janssen, Katleen 2012, 'Rights of Access to Public Sector Information', Masaryk University Journal Law and Technology, vol. 6, no 3.

Van Velze S, Caspers M, Eskens, S \& M van Eechoud, Good practices collection on access to data (with contributions of Austere, L, Broomfield H, Ellis J, Myska M, Lubarda M, Valero-Torrijos J, Pardo-López M, Van Loenen B, Grothe M, Vrecar S, \& De Vries, M), LAPSI, viewed 1 Aug 2015, http://www.lapsi-project.eu/outputs.

De Vries, M. et al. 2011, The Pricing of Public Sector Information, study for the EC, Brussels. 